\title{
BIOREGULATION OF LUBRICIN EXPRESSION BY GROWTH FACTORS AND CYTOKINES
}

\author{
ARC Jones, CR Flannery* \\ Department of Women's Health \& Musculoskeletal Biology, Wyeth Research, Cambridge, MA 02140, USA
}

\begin{abstract}
Lubricin, also commonly referred to as superficial zone protein (SZP) and proteoglycan 4 (PRG4), is a multifaceted, cytoprotective glycoprotein that contributes to the boundary lubrication properties facilitating low friction levels at interfacing surfaces of articular cartilage. Biological processes effecting the gain or loss of lubricin function may therefore have important consequences relevant to joint physiology and pathology. Herein, we describe experiments conducted to extend our understanding of the influence of various cytokines and growth factors on lubricin gene expression and protein secretion in synovial tissues. Exposure of synoviocytes, chondrocytes and cartilage explants to proinflammatory cytokines such as interleukin1 (IL-1) and tumor necrosis factor- $\alpha(\mathrm{TNF}-\alpha)$ results in a marked reduction in the expression and/or abundance of secreted lubricin, with corresponding alterations in the amounts of cartilage-associated (boundary) lubricin. Conversely, treatment with transforming growth factor- $\beta$ (TGF- $\beta$ ) significantly upregulates lubricin synthesis, secretion and cartilage boundary association. Oncostatin $\mathrm{M}$ also appears to be capable of modulating lubricin metabolism, with the potential to induce lubricin synthesis by chondrocytes. Collectively, the results of studies on cytokine and growth factor regulation of lubricin biosynthesis and biodistribution may help provide new insights and therapeutic perspectives for promoting joint function.
\end{abstract}

Key words: articular cartilage, chondrocyte, cytokine, growth factor, lubricin, osteoarthritis, proteoglycan 4 (PRG4), superficial zone protein (SZP), synovial joint, synoviocyte

\author{
Address for correspondence* \\ Carl R. Flannery, Ph.D. \\ Wyeth Research \\ 200 CambridgePark Drive \\ Cambridge, MA 02140, USA
}

Telephone: 617-665-5341

Fax: 617-665-5386

E-mail: cflannery@wyeth.com

\section{Introduction}

Optimal functionality of synovial joints is dependent upon the maintenance of extremely low coefficients of friction between load-accommodating cartilage bearings (Charnley, 1960; Wright and Dowson, 1976). Under normal, healthy conditions, articular cartilage is a resilient biomaterial that sustains a contiguous, well-lubricated surface. However, during degenerative joint diseases such as osteoarthritis (OA), deleterious structural changes are manifested, including progressive cartilage matrix degradation and fibrillation (Buckwalter et al., 2005). Lubricin is a chondroprotective, mucinous glycoprotein which is a product of the proteoglycan 4 (PRG4) gene (HGNC:9364), and is homologous to molecules referred to as superficial zone protein (SZP), megakaryocyte stimulating factor (MSF) precursor, camptodactylyarthopathy-coxa vara-pericarditis (CACP) protein, 'downstream of the liposarcoma-associated fusion oncoprotein' 54 (DOL54) and PRG4 (Flannery et al., 1999; Ikegawa et al., 2000; Jay et al., 2001; Kuroda et al., 1999; Marcelino et al., 1999). Comprised of a multidomain core protein extensively substituted with $\beta$-(13)-Gal-GalNAc oligosaccharides partially capped with NeuAc (Garg and Swann, 1979; Jay et al., 2002), lubricin is a component of synovial fluid which has also been localized to cartilage surfaces and surface layer articular chondrocytes and synoviocytes (Flannery et al., 1999; Jones et al., 2007; Schumacher et al., 1994; Schumacher et al., 1999; Su et al., 2001), meniscus (Schumacher et al., 2005) and tendon (Rees et al., 2002; Sun et al., 2006). Lubricin acts as a vital counteragent against aberrant protein and/or cellular adhesion, infiltration and overproliferation, and serves as a critical boundary lubricant between apposing cartilage surfaces (Jay, 2004; Rhee et al., 2005), such that alterations in its metabolism may profoundly impact joint function. Indeed, genetic disruption of lubricin expression elicits CACP syndrome in humans, with attendant non-inflammatory synovial hyperplasia and fibrosis and premature joint failure (Marcelino et al., 1999), and key features of CACP are recapitulated in lubricin-null mice (Rhee et al., 2005). Furthermore, impaired lubricin expression is associated with the onset of early OA in a sheep meniscectomy model (Young et al., 2006).

An increased understanding of the effects of chondrostimulatory growth factors and cytokines on lubricin expression may help provide an enhanced appreciation of the biological processes governing joint homeostasis and pathophysiology. The proinflammatory cytokine IL-1 has been shown to reduce the expression/ secretion of cartilage-derived lubricin (Flannery et al., 1999; Jones et al., 2006; Khalafi et al., 2007; Ohno et al., 2006; Schmidt et al., 2004a), whereas TGF- $\beta$ conversely 
causes an upregulation of lubricin synthesis (Darling and Athanasiou, 2005; Flannery et al., 1999; Jones et al., 2006; Khalafi et al., 2007; Ohno et al., 2006; Schmidt et al., 2004a). In the current studies, we have confirmed and expanded on these findings by examining the effects of a variety of cytokines and growth factors, including IL-1 $\beta$, TNF- $\alpha$, TGF- $\beta$ and oncostatin M (OSM), on lubricin mRNA and protein expression by articular chondrocytes and synoviocytes. Moreover, we evaluated the effects of these cytoregulatory factors on the biosynthesis/ distribution of both soluble and boundary (cartilage surface-associated) lubricin.

\section{Materials and Methods}

\section{Cartilage explant culture and analysis}

Bovine articular cartilage cores (6mm-diameter) were harvested from the carpal joints of 1-2 week old calves using a biopsy punch. Subchondral bone was trimmed from the cores using a custom stainless steel die, creating explants with a depth of 2-3mm. Cartilage explants were precultured in spinner flasks for 4 days in serum-free DMEM/F12 culture medium (Invitrogen, Carlsbad, CA) containing $50 \mu \mathrm{g} / \mathrm{ml}$ ascorbic acid (Sigma, St. Louis, MO), with a change of medium after 2 days. Explants were then transferred to 24 well plates ( 3 explants/well in $1 \mathrm{ml}$ of serum-free culture medium) and cultured for $48 \mathrm{~h}( \pm 50$ $\mu \mathrm{g} / \mathrm{ml}$ ascorbic acid) in the absence or presence of $10 \mathrm{ng} /$ $\mathrm{ml} \mathrm{IL-1} \beta, 10 \mathrm{ng} / \mathrm{ml}$ TGF- $\beta 1,100 \mathrm{ng} / \mathrm{ml}$ TNF- $\alpha, 10 \mathrm{ng} / \mathrm{ml}$ OSM (R\&D Systems, Minneapolis, MN) or $1 \mu \mathrm{M}$ all-trans retinoic acid (RA; Sigma). Following tissue culture, explant-conditioned media were concentrated using Centricon YM-10 filter units (Millipore, Billerica, MA), adjusted to $50 \mathrm{mM}$ Tris-acetate, $\mathrm{pH} 7.4$, and incubated at $37^{\circ} \mathrm{C}$ for $1 \mathrm{~h}$ with chondroitinase $\mathrm{ABC}(0.3 \mathrm{U} / \mathrm{ml}$; Sigma $)$. For analysis of surface/boundary layer-associated lubricin (Jones et al., 2006a), explants were extracted at $4^{\circ} \mathrm{C}$ for $1 \mathrm{~h}$ with $\mathrm{PBS}$ containing $1.5 \mathrm{M} \mathrm{NaCl}$, then dialysed exhaustively against $\mathrm{dH}_{2} \mathrm{O}$ and lyophilyzed. Extracts and media samples were separated on 4-12\% Tris-glycine SDSPAGE gels (Invitrogen), transferred to Protran BA85 membranes (Whatman, Florham Park, NJ) and analyzed by Western blotting using anti-lubricin monoclonal antibody 6-A-1 (Flannery et al., 1999; Schumacher et al., 1999), raised against native bovine lubricin/SZP (generously provided by Dr. C.E. Hughes and Prof. B. Caterson, Cardiff University, Cardiff, UK).

\section{Chondrocyte and synoviocyte culture and analysis}

Full-depth articular chondrocytes were isolated from normal (non-OA) human articular cartilage (NDRI, Philadelphia, PA) or bovine calf articular cartilage by standard pronase/collagenase digestion (Flannery et al., 1999; Schumacher et al., 1999). Normal (non-OA) human synoviocytes were purchased from Articular Engineering, Northbrook, IL. Following equilibration for $48 \mathrm{~h}$ in culture medium (DMEM/F12 containing 10\% fetal bovine serum and $50 \mu \mathrm{g} / \mathrm{ml}$ ascorbate) in 24 well plates, cells were adapted to serum-free medium ( $\pm 50 \mu \mathrm{g} / \mathrm{ml}$ ascorbate) for $16 \mathrm{~h}$ before stimulation with cytokines/growth factors (as
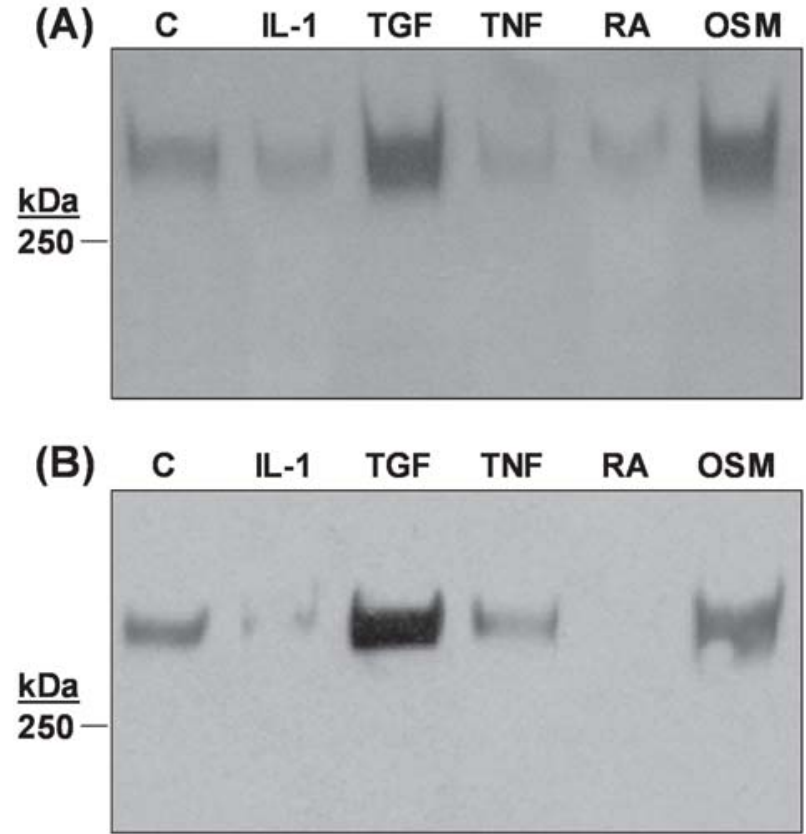

Figure 1. Effects of cytokines and growth factors on cartilage lubricin biosynthesis. Bovine articular cartilage explants were cultured for $48 \mathrm{~h}$ in serum-free medium $(+50 \mu \mathrm{g} / \mathrm{ml}$ ascorbic acid) in the absence $(\mathrm{C}$, control) or presence of $10 \mathrm{ng} / \mathrm{ml} \mathrm{IL-1} \mathrm{(IL-1),} 10 \mathrm{ng} / \mathrm{ml} \mathrm{TGF- \beta 1}$ (TGF), $100 \mathrm{ng} / \mathrm{ml} \mathrm{TNF}-\alpha$ (TNF), $1 \mu \mathrm{M}$ all-trans retinoic acid (RA) or $10 \mathrm{ng} / \mathrm{ml}$ oncostatin M (OSM). Cartilage surface-associated lubricin (A) or soluble lubricin in conditioned media (B) were analyzed by Western blotting with monoclonal antibody 6-A-1, raised against native bovine lubricin/SZP.

described above for cartilage explant cultures). RNA was extracted in triplicate (RNeasy + DNAse I, Qiagen, Valencia, CA) after $24 \mathrm{~h}$ for quantitative, real-time RT-PCR analysis (ABI PRISM 7700 Sequence Detection System; Applied Biosystems, Foster City, CA). For bovine samples, assays were performed using primer/probe sets specific for bovine lubricin (Grad et al., 2005) and GAPDH (Wong et al., 2003). Human samples were analyzed using TaqMan ${ }^{\circledR}$ gene expression assays (Applied Biosystems) specific for human lubricin (Hs00195140_m1, targeting exons 3/4 or Hs00981633_m1, targeting exons 7/8) and GAPDH (Hs99999905_m1). Lubricin mRNA levels were normalized to GAPDH and expressed relative to control (untreated) culture levels $\left(\Delta \Delta \mathrm{C}_{\mathrm{T}}\right.$ method; Applied Biosystems). Human chondrocyte or synoviocyte conditioned media were harvested after $48 \mathrm{~h}$ and analyzed by Western blotting using a polyclonal anti-lubricin antibody (Wyeth Ab 378), directed toward a peptide epitope encoded within exon 3 of human lubricin.

\section{Results}

\section{Effects of cytokine and growth factor treatment on lubricin synthesis by bovine cartilage explants}

Stimulation of cultured calf articular cartilage explants with IL- $1 \beta$, TGF- $\beta$, TNF- $\alpha$, RA or OSM induced quantitative alterations in the retention of lubricin at the cartilage 
surface, as shown in Fig. 1A. TGF- $\beta$ and OSM increased lubricin accumulation, whereas a decrease was seen following treatment with IL-1 $\beta$, TNF- $\alpha$ and RA. A similar lubricin biosynthetic profile was observed for explantconditioned media (Fig. 1B). Exclusion of ascorbic acid from the culture media lowered the levels of soluble lubricin in conditioned media, as well as the amount of lubricin associated with cartilage surfaces (data not shown), accordant with other studies that document the upregulation of lubricin synthesis by ascorbic acid (Schmidt et al., 2004b).

\section{Dose-dependent effects of cytokines and growth factors on bovine chondrocyte lubricin mRNA expression}

In agreement with the results described above, omission of ascorbic acid from cell culture medium reduced lubricin mRNA expression by bovine chondrocytes (Fig. 2). For cultures maintained in the presence of ascorbic acid, inhibition of lubricin mRNA synthesis by IL-1 was observed at $10 \mathrm{ng} / \mathrm{ml}$, whereas TGF- $\beta$-mediated enhancement of lubricin mRNA levels was apparent, occurring maximally ( $\sim$-fold) after stimulation at a concentration of $2 \mathrm{ng} / \mathrm{ml}$. Lubricin mRNA expression was not observed to be significantly decreased in bovine chondrocyte monolayer cultures by TNF- $\alpha(100 \mathrm{ng} / \mathrm{ml})$ or RA $(1 \mu \mathrm{M})$ treatments (data not shown), suggesting that the reductions in lubricin protein levels in response to these agents observed in cartilage cultures (see Fig. 1) might involve post-translational mechanism(s) of turnover/ degradation. In comparison, treatment of bovine chondrocytes for $24 \mathrm{~h}$ with $2 \mathrm{ng} / \mathrm{ml}$ and $10 \mathrm{ng} / \mathrm{ml} \mathrm{OSM}$ provoked a dose-dependent increase in lubricin mRNA expression (Fig. 2), concordant with the effects of this cytokine on lubricin protein accumulation in bovine cartilage explants (Fig. 1).

\section{Differential regulation of lubricin biosynthesis by human chondrocytes and synoviocytes}

Stimulation of human chondrocytes and synoviocytes with $10 \mathrm{ng} / \mathrm{ml} \mathrm{IL-1}$ for $24 \mathrm{~h}$ reduced lubricin mRNA levels by $\sim 50-60 \%$ compared to untreated controls (Fig. 3), and correlative changes were observed for lubricin protein secretion (Fig. 4). TGF- $\beta$ induced an increase in lubricin mRNA ( $\sim$-fold) and protein synthesis by both cell types. No significant effects on lubricin biosynthesis were observed following RA treatment, whereas TNF- $\alpha$ and OSM appeared to generate a cell-specific response in human chondrocytes and synoviocytes. Thus, TNF- $\alpha$ reduced lubricin expression by human chondrocytes, but not human synoviocytes, while OSM increased its synthesis in chondrocytes, but not synoviocytes (see Figs. 3 and 4). Two different lubricin-specific primer/probe sets, targeting either exons $3 / 4$ or exons $7 / 8$, were used for the quantitative RT-PCR analyses (Fig. 3), since previous studies have described alternative mRNA splice variants of the PRG4 gene (Flannery et al., 1999; Jay et al., 2001; Rees et al., 2002). No significant differences were observed within treatment groups, however, when comparing the relative expression of these regions of lubricin mRNA.

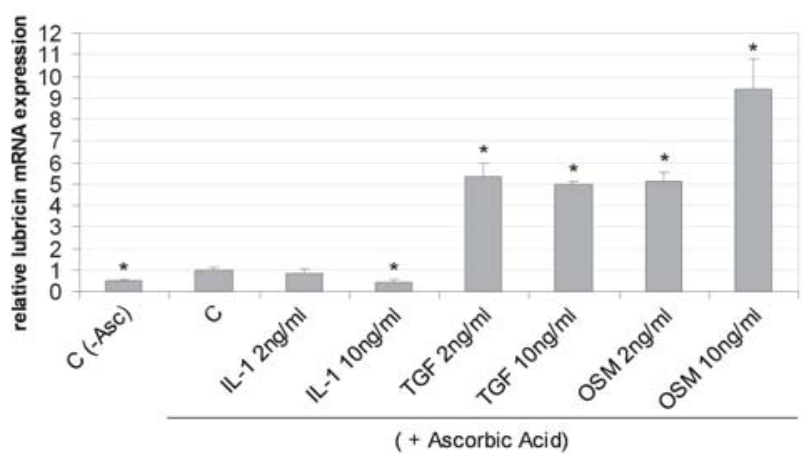

Figure 2. Quantitation of lubricin mRNA levels in bovine chondrocytes following cytokine and growth factor stimulation. Bovine articular chondrocytes were cultured for $24 \mathrm{~h}$ in serum-free medium in the absence (C, control) or presence of various doses of growth factors and cytokines as indicated (also see legend to Fig. 1). Ascorbic acid $(50 \mu \mathrm{g} / \mathrm{ml})$ was included in the culture medium, except as indicated (-Asc). Lubricin mRNA levels, analyzed by real-time quantitative RTPCR, are expressed relative to the levels in control cultures. Values are the mean and standard deviation of 3 separate analyses. *Significantly different to control $(P<0.05$; Student's $T$-test $)$.

\section{(A)}

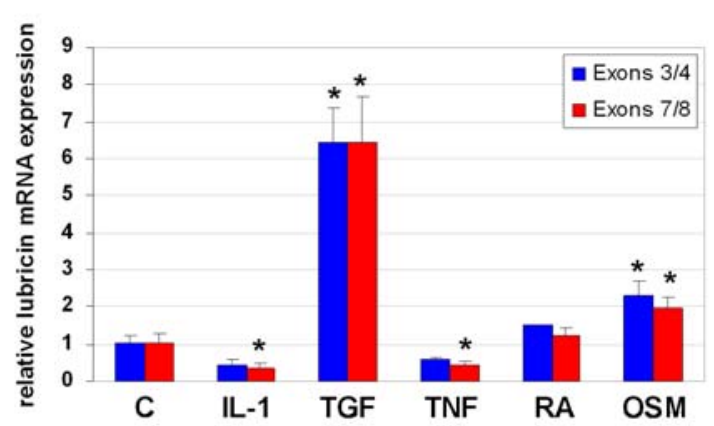

(B)

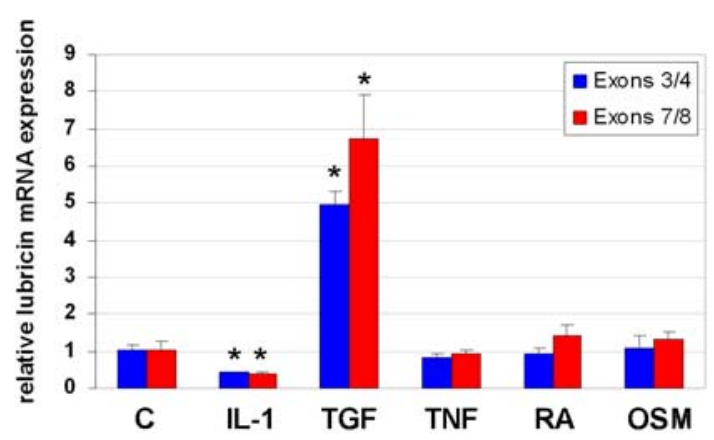

Figure 3. Quantitative RT-PCR analysis of lubricin mRNA expression by human chondrocytes (A) and synoviocytes (B). Cells were cultured for $24 \mathrm{~h}$ in serumfree medium $(+50 \mu \mathrm{g} / \mathrm{ml}$ ascorbic acid) in the absence (C, control) or presence of cytokines and growth factors as described in the legend to Fig. 1. Two different lubricin primer/probe sets were used to generate and quantify amplicons derived from exons $3 / 4$ or exons $7 / 8$. Lubricin mRNA levels are expressed relative to the levels in control cultures. Values are the mean and standard deviation of 3 separate analyses. *Significantly different to control $(P<0.05$; Student's $T$-test $)$. 

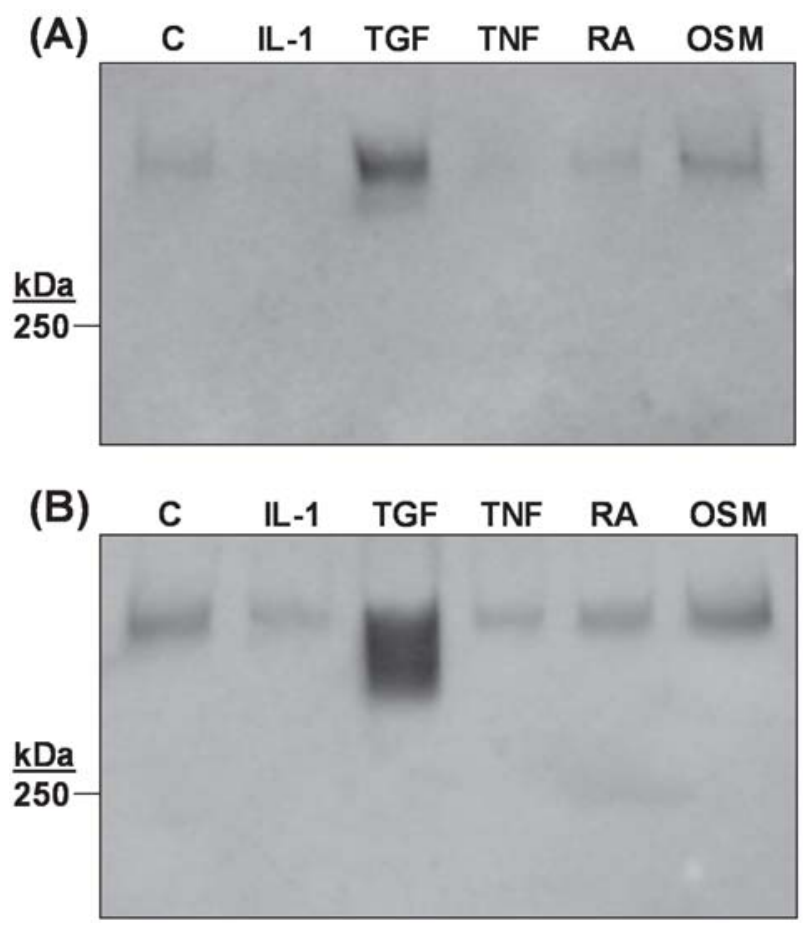

Figure 4. Cytokine- and growth factor-mediated regulation of lubricin secretion by human chondrocytes (A) and synoviocytes (B). Cells were cultured for $48 \mathrm{~h}$ in serum-free medium ( $+50 \mu \mathrm{g} / \mathrm{ml}$ ascorbic acid) in the absence $(\mathrm{C}$, control) or presence of cytokines and growth factors as described in the legend to Fig. 1. Conditioned media were analyzed by Western blotting with a polyclonal anti-lubricin antibody, directed toward a peptide epitope encoded within exon 3 of human lubricin.

\section{Discussion}

The synovial "tribosome", comprising macromolecules such as lubricin and aggrecan, facilitates lubrication and fluid pressurization of articular cartilage, thereby contributing to the maintenance of proficient joint functionality (Ateshian et al., 2003; Sah, 2004). In addition to its localization at cartilage surfaces, lubricin occurs as a soluble component of synovial fluid, wherein it may reside as a boundary lubricant "reservoir", with the ability to (re)adhere at tissue interfaces (Jones et al., 2007). Dysregulation of lubricin metabolism, for example under the influence of elevated cytokine concentrations in diseased or damaged joints (Irie et al., 2003; Smith et al., 1997), might thereby lead to lubrication deficiencies and loss-of-function.

Exposure of articular cartilage superficial zone chondrocytes, mandibular condyle cartilage and articular cartilage explants to IL-1 has previously been shown to downregulate the levels of secreted lubricin/SZP (Flannery et al., 1999; Jones et al., 2006; Khalafi et al., 2007; Ohno et al., 2006; Schmidt et al., 2004a), through mechanisms which could include diminished expression as well as enhanced degradation/turnover. In the studies described herein, treatment of bovine articular cartilage explants with IL-1 decreased the levels of both cartilage surface- associated and soluble lubricin (Fig. 1), and a similar effect on lubricin secretion occurred in human chondrocyte and synoviocyte cultures (Fig. 4). A corresponding decrease in lubricin mRNA expression in response to IL-1 was also observed for cultured chondrocytes and synoviocytes (Figs. 2 and 3), suggesting that transcriptional repression may, at least in part, modulate these effects. TNF- $\alpha$ and RA also reduced cartilage lubricin levels, however treatment with OSM, which is typically considered as a chondrodisruptive cytokine (Cawston et al., 1998; Hui et al., 1996), enhanced the expression and accumulation of lubricin in cartilage explant and chondrocyte cultures, although synoviocyte lubricin synthesis in the presence of OSM was not apparently altered (see Figs. 1-4).

Physiologically, lubricin contributes to capacitate cartilage with a remarkably low coefficient of friction (Jay, 2004), and is involved in preventing cellular adhesion to cartilage surfaces (Rhee et al., 2005). It will therefore be of considerable interest to further address whether changes in lubricin biosynthesis in response to growth factors and cytokines are reflected in relevant functional alterations (i.e. frictional properties). From a therapeutic perspective, it would appear that strategies to rescue lubricin dysfunction could be beneficial in the treatment of degenerative joint diseases such as OA. The upregulation observed for lubricin expression upon TGF- $\beta$ stimulation, as demonstrated here and by others (Darling and Athanasiou, 2005; Flannery et al., 1999; Jones et al., 2006; Khalafi et al., 2007; Ohno et al., 2006; Schmidt et al., 2004a), may advocate potential mechanisms for restoring lubricin deficiencies. Alternately, or additionally, cartilage endurance might also be enhanced by the induction of lubricin synthesis in response to appropriate biophysical stimuli (Grad et al., 2005; Grad et al., 2006; Nugent et al., 2006a; Nugent et al., 2006b; Wong et al., 2003). The capacity for recombinant lubricin to effectively bind to, and lubricate articular cartilage surfaces (Gleghorn et al., 2006; Jones et al., 2007) suggests further evident therapeutic implications for delivery of applicable biolubricant formulations.

\section{Acknowledgments}

We would like to thank and acknowledge colleagues and collaborators at Wyeth Research (C. Keohan, L. Fitz, M. Majumdar, E. Morris, R. Sheldon, R. Zollner), Cardiff University (B. Caterson, C. Hughes) and Cornell University (L. Bonassar, J. Gleghorn).

\section{References}

Ateshian GA, Soltz MA, Mauck RL, Basalo IM, Hung CT, Lai WM (2003) The role of osmotic pressure and tension-compression nonlinearity in the frictional response of articular cartilage. Transport in Porous Media 50: 5-33.

Buckwalter JA, Mankin HJ, Grodzinsky AJ (2005) Articular cartilage and osteoarthritis. Instr Course Lect 54: 465-480. 
Cawston TE, Curry VA, Summers CA, Clark IM, Riley GP, Life PF, Spaull JR, Goldring MB, Koshy PJ, Rowan AD, Shingleton WD (1998) The role of oncostatin M in animal and human connective tissue collagen turnover and its localization within the rheumatoid joint. Arthritis Rheum 41: $1760-1771$.

Charnley J (1960) The lubrication of animal joints in relation to surgical reconstruction by arthroplasty. Ann Rheum Dis 19: 10-19.

Darling EM, Athanasiou KA (2005) Growth factor impact on articular cartilage subpopulations. Cell Tissue Res 322: 463-473.

Flannery CR, Hughes CE, Schumacher BL, Tudor D, Aydelotte MB, Kuettner KE, Caterson B (1999) Articular cartilage superficial zone protein (SZP) is homologous to megakaryocyte stimulating factor precursor and is a multifunctional proteoglycan with potential growthpromoting, cytoprotective, and lubricating properties in cartilage metabolism. Biochem Biophys Res Commun 254: 535-541.

Garg HG, Swann DA (1979) The structure of the Oglycosylically-linked oligosaccharide chains of LPG-I, a glycoprotein present in articular lubricating fraction of bovine synovial fluid. Carbohydrate Res 78: 79-88.

Gleghorn JP, Jones ARC, Flannery CR, Bonassar LJ (2006) Lubrication of articular cartilage by recombinant human lubricin. Trans Orthop Res Soc 31: 1502.

Grad S, Lee CR, Gorna K, Gogolewski S, Wimmer MA, Alini M (2005) Surface motion upregulates superficial zone protein and hyaluronan production in chondrocyteseeded three-dimensional scaffolds. Tissue Eng 11: 249256.

Grad S, Lee CR, Wimmer MA, Alini M (2006) Chondrocyte gene expression under applied surface motion. Biorheology 43: 259-269.

Hui W, Bell M, Carroll G (1996) Oncostatin M (OSM) stimulates resorption and inhibits synthesis of proteoglycan in porcine articular cartilage explants. Cytokine 8: 495500 .

Ikegawa S, Sano M, Koshizuka Y, Nakamura Y (2000) Isolation, characterization and mapping of the mouse and human PRG4 (proteoglycan 4) genes. Cytogenet Cell Genet 90: 291-297.

Irie K, Uchiyama E, Iwaso H (2003) Intraarticular inflammatory cytokines in acute anterior cruciate ligament injured knee. Knee 10: 93-96.

Jay GD (2004) Lubricin and surfacing of articular joints. Curr Opin Orthop 15: 355-359.

Jay GD, Harris DA, Cha C-J (2002) Boundary lubrication by lubricin is mediated by O-linked beta(1-3) Gal-GalNac oligosaccharides. Glycoconjugate J 18: 807815.

Jay GD, Tantravahi U, Britt DE, Barrach HJ, Cha C-J (2001) Homology of lubricin and superficial zone protein (SZP): products of megakaryocyte stimulating factor (MSF) gene expression by human synovial fibroblasts and articular chondrocytes localized to chromosome 1q25. J Orthop Res 19: 677-687.

Jones ARC, Gleghorn JP, Hughes CE, Fitz LJ, Zollner R, Wainwright SD, Caterson B, Morris EA, Bonassar LJ,
Flannery CR (2007) Binding and localization of recombinant lubricin to articular cartilage surfaces. J Orthop Res 25: 283-292.

Jones ARC, Sheldon R, Keohan C, Majumdar MK, Morris EA, Flannery CR (2006) Cytokine-regulated metabolism of lubricin in situ in cartilage explant cultures. Trans Orthop Res Soc 31: 143.

Khalafi A, Schmid TM, Neu C, Reddi AH (2007) Increased accumulation of superficial zone protein (SZP) in articular cartilage in response to bone morphogenetic protein-7 and growth factors. J Orthop Res 25: 293-303.

Kuroda M, Wang X, Sok J, Yin Y, Chung P, Giannotti JW, Jacobs KA, Fitz LJ, Murtha-Riel P, Turner KJ, Ron D (1999) Induction of a secreted protein by the myxoid liposarcoma oncogene. Proc Natl Acad Sci USA 96: 50255030 .

Marcelino J, Carpten JD, Suwairi WM, Gutierrez OM, Schwartz S, Robbins C, Sood R, Makalowska I, Baxevanis A, Johnstone B, Laxer RM, Zemel L, Kim CA, Herd JK, Ihle J, Williams C, Johnson M, Raman V, Alonso LG, Brunoni D, Gerstein A, Papadopoulos N, Bahabri SA, Trent JM, Warman ML (1999) CACP, encoding a secreted proteoglycan, is mutated in camptodactyly-arthropathycoxa vara-pericarditis syndrome. Nature Genet 23: 319322.

Nugent GE, Aneloski NM, Schmidt TA, Schumacher BL, Voegtline MS, Sah RL (2006a) Dynamic shear stimulation of bovine cartilage biosynthesis of proteoglycan 4. Arthritis Rheum 54: 1888-1896.

Nugent GE, Schmidt TA, Schumacher BL, Voegtline MS, Bae WC, Jadin KD, Sah RL (2006b) Static and dynamic compression regulate cartilage metabolism of proteoglycan 4 (PRG4). Biorheology 43: 191-200.

Ohno S, Schmid T, Tanne Y, Kamiya T, Honda K, Ohno-Nakahara M, Swentko N, Desai TA, Tanne K, Knudson CB, Knudson W (2006) Expression of superficial zone protein in mandibular condyle cartilage. Osteoarthritis Cartilage 14: 807-813.

Rees SG, Davies JR, Tudor D, Flannery CR, Hughes CE, Dent CM, Caterson B (2002) Immunolocalisation and expression of proteoglycan 4 (cartilage superficial zone proteoglycan) in tendon. Matrix Biol 21: 593-602.

Rhee DK, Marcelino J, Baker M, Gong Y, Smits P, Lefebvre V, Jay GD, Stewart M, Wang H, Warman ML, Carpten JD (2005) The secreted glycoprotein lubricin protects cartilage surfaces and inhibits synovial cell overgrowth. J Clin Invest 115: 622-631.

Sah RL (2004) Interface and bulk regions in the repair, regeneration, and replacement of articular cartilage. J Musculoskel Neuron Interact 4: 393-395.

Schmidt TA, Schumacher BL, Han EH, Klein TJ, Voegtline MS, Sah RL (2004a) Synthesis and secretion of lubricin/superficial zone protein by chondrocytes in cartilage explants: modulation by TGF-beta1 and IL1alpha. Trans Orthop Res Soc 29: 577.

Schmidt TA, Schumacher BL, Klein TJ, Voegtline MS, Sah RL (2004b) Synthesis of proteoglycan 4 by chondrocyte subpopulations in cartilage explants, monolayer cultures, and resurfaced cartilage cultures. Arthritis Rheum 50: 2849-2857. 
Schumacher BL, Block JA, Schmid TM, Aydelotte MB, Kuettner KE (1994) A novel proteoglycan synthesized and secreted by chondrocytes of the superficial zone of articular cartilage. Arch Biochem Biophys 311: 144-152.

Schumacher BL, Hughes CE, Kuettner KE, Caterson B, Aydelotte MB (1999) Immunodetection and partial cDNA sequence of the proteoglycan, superficial zone protein, synthesized by cells lining synovial joints. J Orthop Res 17: 110-120.

Schumacher BL, Schmidt TA, Voegtline MS, Chen AC, Sah RL (2005) Proteoglycan 4 (PRG4) synthesis and immunolocalization in bovine meniscus. J Orthop Res 23: 562-568.

Smith MD, Triantafilou S, Parker A, Youssef PP, Coleman M (1997) Synovial membrane inflammation and cytokine production in patients with early osteoarthritis. J Rheumatol 24: 365-371.

Su J-L, Schumacher BL, Lindley KM, Soloveychik V, Burkhart W, Triantafillou JA, Kuettner KE, Schmid TM (2001) Detection of superficial zone protein in human and animal body fluids by cross-species monoclonal antibodies specific to superficial zone protein. Hybridoma 20: 149157.

Sun Y, Berger EJ, Zhao C, Jay GD, An K-N, Amadio PC (2006) Expression and mapping of lubricin in canine flexor tendon. J Orthop Res 24: 1861-1868.

Wong M, Siegrist M, Goodwin K (2003) Cyclic tensile strain and cyclic hydrostatic pressure differentially regulate expression of hypertrophic markers in primary chondrocytes. Bone 33: 685-693.

Wright V, Dowson D (1976) Lubrication and cartilage. J Anat 121: 107-118.

Young AA, McLennan S, Smith MM, Smith SM, Cake MA, Read RA, Melrose J, Sonnabend DH, Flannery CR, Little CB (2006) Proteoglycan 4 downregulation in a sheep meniscectomy model of early osteoarthritis. Arthritis Res Ther 8: R41.

\section{Discussion with reviewers}

S. Grad: Ascorbic acid has been shown to increase the cells' basic lubricin expression and synthesis. However, is ascorbic acid also required for their lubricin response to growth factors?

Authors: We have conducted experiments to stimulate calf cartilage explants as described in this manuscript, but with the omission of ascorbic acid from the culture media. We found that the absence of ascorbic acid does not appear to affect the relative changes in lubricin protein expression modulated by growth factors. However, we did observe an overall decrease in lubricin protein levels in the absence of ascorbic acid, indicating that upregulation of lubricin expression by ascorbic acid is additive, as opposed to synergistic.

S. Grad: It is known that OSM can synergize the action of other inflammatory mediators such as IL-1 or TNF- $\alpha$. Inversely, OSM has also been shown to antagonize certain effects of IL-1. What is the lubricin response to cytokine combinations containing OSM? Does OSM act synergistically or antagonistically to IL-1?

Authors: The enhanced lubricin expression observed in response to OSM is interesting, given its documented capacity to reduce cartilage proteoglycan synthesis and elevate cartilage matrix degradation. It will be of interest to further investigate the interactions, potentially dosedependent, between OSM and other chondroregulatory cytokines/growth factors. 